\title{
Same sex couples and marriage: negotiating relational landscapes with families and friends
}

\section{Carol Smart}

\begin{abstract}
Focusing on the decision to enter into a marriage and/or to conduct a commitment ceremony, this paper explores how same-sex couples negotiate their relationships with both family and friends at the point at which they make decisions about who to invite to their ceremony. The ceremony is argued to be a 'fateful moment' at which point lesbians and gay men necessarily take stock of relationships which are meaningful to them. It is argued that the data from the qualitative interviews on which this paper is based add to the on-going debates about the meaning and significance of both (given) families and (chosen) friends for same-sex couples and suggests that it is sociologically important to recognise both the blurring of the boundaries between these categories as well as the meanings that individuals themselves bring to an understanding of the significance of these relationships.
\end{abstract}

\section{Introduction}

The issue of civil partnership or same-sex marriage has generated considerable discussion in recent years (Auchmuty, 2004; Boyd and Young, 2003; Jeffreys, 2004). A number of themes have been aired and perhaps the most prominent has been the equal rights/human rights dimension which has been such a strong element in bringing about changes to national laws (Stonewall, 2004; Murphy, 2002, 2004; Bell, 2004). But there has also been the opposing issue of how entry into marriage, ${ }^{1}$ notwithstanding human rights, is a means to de-radicalise and normalise queer or non-conventional relationships which operate with different values and codes to those found in heterosexual relationships (Warner, 1999; Dunne, 1997; Stychin, 2003; Bech, 1992; Wise and Stanley, 2004; Weeks et al., 2001). Auchmuty for example argues,

The liberal agenda may, indeed, grant us rights to hitherto heterosexual privileges. But unless we are careful, it will do so on its terms, naturally assuming that heterosexual values are the norm, if not the best. (Auchmuty, 2004: 124) 
Stychin (2003) is less concerned with assimilation than with the ways in which laws governing sexual and intimate relationships may work to limit future possibilities and developments. He argues,

[My] concern ... is that the disciplinary, normalising function of liberal law reform may constrain us, by acting to limit the variety of ways of living - of styles of life - which sexual dissidents historically have developed. That is, my fear is that legal recognition may limit our ability to recognise that we can construct our lives so as to defy the categories which law traditionally has sought to impose upon us. (2003: 4)

What is notable about these debates is that so many of the contributions have been the concern of either academic lawyers and/or political activists who argue the issues at a level of politics and principle. The campaigning tone of much of this work, and particularly the recourse to the language of 'us' (with its implied commonality of view and purpose) is a significant feature and it reflects an important tradition in radical or oppositional academic scholarship. However, there are limitations to this approach sociologically speaking because there may be other voices and other concerns which are less vocal, which are not part of an already established political or academic community, and which may present a slightly different or more nuanced $^{2}$ world view. So it may now be timely to add a different dimension to the existing debate; one that draws from the views and feelings of gay and lesbian couples ${ }^{3}$ who have been through a commitment ceremony or have registered their partnerships, and who also propose to enter into civil partnerships. In this paper I will concentrate particularly on the question of the significance of marriage for a couple's relationship with wider kin, particularly parents, and with friends. This is because a decision to marry is a relational process and breaking the news to friends and family constitutes a phase of discussion and often re-negotiation of relationships. I am therefore interested in how these decisions may reconfigure close personal relationships rather than on concentrating on more macro issues of de-radicalisation and the broader political significance of these moves. In the first section of the paper I shall describe the study ${ }^{4}$, the methodology and some of the limitations faced. I shall then discuss recent thinking on the concepts of 'family', 'friends' and 'families of choice' which will lead into a discussion of the ways in which the couples and individuals in the sample spoke of their relationships with their families and friends in order to explore how they negotiated these relationships. What transpired was a complex picture in which some couples were warmly embraced by biological family, but somewhat cold shouldered by friends; while with others, friends offered the most supportive context while biological family remained at a distance. In the conclusion I shall explore what this study contributes to recent debates on shifting conceptions of personal relationships. 


\section{The study ${ }^{5}$}

The study was based on in-depth qualitative interviews with same-sex couples and lesbian and gay individuals who had gone through a commitment ceremony or who had registered their partnership with their Local Authority. At the time of the interviews Civil Partnership had not been introduced although in the later stages of the study the new legislation was passed by Parliament and was waiting to be implemented. This means that ours was a particularly interesting sample because these individuals and couples were in a kind of vanguard, forging their own ceremonies and making their relationships public before the State formalised system was in place. In this way we feel that we have captured a very important moment in the history of changing homosexualities. Our study will hopefully provide a benchmark for later studies on Civil Partnership and it will be interesting to discover whether motivations and decision making processes will change or be different with the introduction of the formal, legally binding system (see also Clarke et al., 2006).

We conducted 54 interviews in total, 37 with couples and 17 with individuals. For the sake of simplicity I shall speak here mainly of the sample as comprising information about 54 relationships because we gathered information on the couples even though in some instances we spoke to only one member of the dyad. Of the 37 couple interviews 17 were conducted with lesbian couples and 10 with gay male couples. The 17 solo interviews comprised 7 lesbians and 10 gay men. This means that not only did we recruit fewer men altogether, but that men were more likely than women to be interviewed alone than in couples. We gave our interviewees the choice of whether to be interviewed together or separately and typically the reasons given for being interviewed alone were to do with partners' different work patterns, partners being away and occasionally because partners simply did not want to participate in the study. We did not want to lose the opportunity of interviewing these individuals and hearing about their ceremonies because of the impossibility of involving their partners in the interviews. However, it should be recognised that we have data of slightly different quality arising from the solo and the couple interviews. This is because interviewing couples together can create a different dynamic to solo interviews. Couples could 'bounce' off each other in various ways and this could produce recollections which might not have emerged if the interaction had not occurred. We also gathered more information on the families from both 'sides' with couples as typically each spoke of their own family of origin in turn. The possible disadvantage of the couple interview, however, was that we probably heard more consensual accounts than we might have done if we had interviewed everyone separately. Unfortunately the ideal scenario of interviewing couples separately and then again together was not feasible given the scope of the study (Mansfield and Collard, 1988). 
The majority of our interviewees were between 30 and 49 years of age and some couples had been together for as long as thirty years. All except one respondent described him or herself as white (mainly White British, White English, White Scottish etc) and our sample was disproportionately 'middle class' (a ratio of 8:1) taking into account factors of education level, the nature of employment and housing tenure. We contacted our respondents mainly through the gay media (eg Gay Times ${ }^{6}$, Diva) and websites (eg Pink Wedding Waiting List, Stonewall) and through leaflets distributed at Gay Pride marches, bookshops, local groups, and religious groups. Our impression of our respondents was that they were attached to local gay or lesbian networks which might be work based, community based or 'hobby' based. Thus some were involved in lesbian mothers' groups while others worked for HIV support organisations and yet others simply went walking together. Finally, all the names used in this paper are pseudonyms and although ages are included any references which might compromise anonymity have been removed.

\section{Friends, families and families of choice}

In an article which criticises the implicit heteronormativity of much sociological work on families and family practices, Roseneil and Budgeon (2004) argue,

Considerable evidence from sociological and anthropological research suggests that friendship, as both a practice and an ethic, is particularly important in the lives of lesbians and gay men. Networks of friends, which often include ex-lovers, form the context within which lesbians and gay men lead their personal lives, offering emotional continuity, companionship, pleasure and practical assistance. (2004: 137-8)

These authors point out that there has been a strong tendency for contemporary sociology (dealing mainly with the lives of heterosexuals) to overlook friendship and they argue that what is needed is the development of a separate subfield within the discipline precisely to rectify this omission and to give due consideration to the significance of friends. They indicate that while studies of (heterosexual) personal lives have given primacy to biological families and intimate couple relationships, many studies on same-sex relationships and gay/lesbian lives have identified friendship as providing a greater source of support and intimacy than biological kin. It is in these studies that friendship can be seen as comprising the most significant form of intimacy while family fades slightly into the background. As Weeks et al. state:

Many non-heterosexuals, particularly lesbians, dislike using the term 'family' because of its historic baggage and oppressive heterosexual connotations.... For many others, friendship circles are spoken about as equivalent to the idealised family (and infinitely preferable to the real 
one)... [T] he use of the term 'family' suggests a strongly perceived need to appropriate the sort of values and comforts that the family unit is supposed to embody, even if it regularly fails to do so ... (2001: 10, emphasis added)

There is, however, a tendency in the literature for the concept of friends to signify (almost axiomatically) good quality relationships while biological families can signify impoverished or even hostile relationships. Yet as many authors ${ }^{7}$ have pointed out, in everyday speech the term family is still used to suggest close and binding relationships because, even if the families we live (or lived) with are problematic, there is an investment in the cultural imaginary of ideal families - or families we live by (Gillis, 1996). Thus it is not unusual for people to speak of best friends being like brothers or sisters, and equally of brothers and sisters as being like best friends (Pahl and Pevalin, 2005). This kind of conceptual mobility and fluidity is captured to a large extent in the term 'families of choice' which has been developed substantially by Weston (1997) and Weeks et al. (2001). In its original usage the concept of families of choice appeared to suggest that friends replace biological family as kin in the lives of same sex couples (Nardi, 1992) but more recent studies have suggested that families of choice combine both 'chosen' biological kin with friends who have become identified as kin (Weston, 1997; Weeks et al., 2001). In other words although people (usually) know precisely who their kin are, they can be seen to jumble them up in colloquial speech and move quite easily between categories (almost demolishing them as they go) because they are often more concerned to identify who matters to them than to follow strict rules of genealogy. Take the following quotations on the subject of arrangements for ceremonies of commitment as examples of this practice:

Rachel (45 yrs): Yes we tried to do it so that we had my biological family and Celia's and then my chosen family I mean Edith's ex sister-in-law but she was my best friend and then Mandy and Lynn are two friends who are committed to each other but were there when we met so they spoke as well.

Cameron (44 yrs): I have one niece and Samuel has four nieces and nephews and he chose one of those nieces to do a reading, two of our closest friends did readings. And also in terms of how we structured it having got everybody sat down we actually got Samuel's mother to bring me in and my mother to bring him in. My father was around anyway but he was happy being sat on the front row next to my mother's seat. It did not worry him that he was not doing that but each other mum brought the other one of us in so they were fully involved and they sort of led us out afterwards. And when it came to the speeches afterwards we chose Samuel's younger sister to be our equivalent to a best man. Because I had a brother and Samuel has another sister and a brother. But we settled on her above friends and above 
any other brother and sister as being the person who we thought we knew best and who would be the most perceptive in what she had to say. So she spoke, so we involved family in that way as well.

Morris (36 yrs): Because for me the best man is probably my sister.

As Pahl and Spencer (2004) have suggested it may now be more appropriate to think in terms of a complex continuum of relationships rather than discrete categories. They have therefore developed the concept of suffusion in order to conceptualise how boundaries between, and nuances of closeness, can take different forms and shapes. This concept introduces the idea of relationships as more or less 'friend-like' and more or less 'family-like' and allows them to slide between the two depending on various interacting qualities such as affection or responsibility or choice. But Pahl and Spencer also point out that while they found evidence of some blurring of boundaries between friends and family, it would be unwise to see this as a general trend because some people do retain clear distinctions between these relationships. Indeed not all of the couples we interviewed used the concept of family of choice (or chosen family) and some did adhere to the idea that there were distinct clusters of people in their networks, with friends in one domain and family in another. These tended to be individuals who had cut off all contact with parents and sibling or who, if retaining some contact, did not actually have an ongoing relationship at the time of the interview. But it would be problematic to assume that only people with poor family relationships operated with this kind of clear distinction. And it is equally important to stress temporality in our understanding of these relationships because these relationships are unlikely to be static and even poor or difficult relationships may be rekindled, while close ones may deteriorate over the life course. Relationships with kin - particularly parents - are rarely laid completely to rest no matter how bad they might be. They can impose themselves at times like Christmas or Hanukah or other 'family' times, or at the death of a grandparent or other relative, or when some other major event occurs in the life course. Equally we should be aware that relationships with friends are not static. They may decline in significance (Pahl and Pevalin, 2005) as new events occur or as previously shared perspectives cease to be mutual. Or it may be that although friendships remain central in a life course, actual personnel may change. The shifts and changes that occur in a circle of friends may therefore be less visible because an individual still has friends, and it may also be easier emotionally to move away from (some) friends than it is to move away from core biological kin. This suggests that it is important to emphasise both given and chosen families as fluid rather than seeing one as the replacement for the other, or seeing one as a haven in the flight from the other. As Finch and Mason $(1993,2000)$ have shown these relationships are a process of negotiation, and feelings about relatives do not flow from the mere fact of being related or being kin, but arise from a complex exchange of practices, situations and obligations over time. 
As we see it, kinship is continually being made or crafted by people in different and changing social locations, with different experiences, concerns, gazes and existences.... we are saying that the English context produces kinship that is both fluid and dynamic, and that this is the norm not the exception. (2000: 167)

\section{The impact of marriage on these relationships}

If we consider a marriage to be a fateful moment (Giddens, 1992) in people's lives, then this is also likely to be a moment for taking stock and making decisions about future and past relationships - especially with families of origin. This is not to prioritise biological families, but simply to recognise that thoughts about, if not the actual presence of, such kin are almost unavoidable at such a culturally meaningful moment. Moreover, fateful moments are associated with periods of reflection which can be quite profound. This may produce a desire for reconciliation or to offer an olive branch and it may induce a desire for inclusion into the event itself. At a more mundane level, a wedding gives rise to decisions about who to tell, who to invite (either to the ceremony or the party afterwards), and how to prepare oneself emotionally for possible derision, rejection or distress (Lewin, 1998) as well as good will. There arise issues about whether to invite parents on both sides, whether to invite sibling, cousins, aunts and uncles, and whether to mix parents with LGBT friends. In this situation, many of the couples we interviewed thought not only about how to manage the day so that it would be the best possible arrangement for themselves, but they also considered how comfortable their kin might be on meeting friends - or alternatively how unpleasant it might be for their LGBT friends to be confronted by thinly disguised homophobic responses from some relatives.

In our sample 35 individuals invited both of their parents, 1 person invited just her mother, 6 were undecided, in 20 cases parents were deceased, and in 9 cases we had no information. This left only 20 individuals who decided definitely not to invite their parents. Everyone, except the two couples who invited no one at all to their ceremonies, invited some friends. The decision processes that couples went through express exactly what Mason (2004) has described as relational thinking. That is to say that they negotiated their way through multi-dimensional webs of relationships, being attentive to the different needs of different people. In some instances it proved too difficult and ceremonies were very small affairs, and in some cases only friends were invited because it was important for everyone to feel comfortable.

June (59 yrs): I think that unless you are very lucky with your friends and family - I know that on an occasion like that where I just want to be able to really relax, be myself, I just want other lesbians there or there could have been gay men and lesbians but it happens that most of our friends are 
lesbians because I think still the only time when I can truly feel myself and be with Grace in an incredibly comfortable, you know just feel totally comfortable, is when we are with other lesbians - it's sad but true. So it was just our friends.

But the process provides a unique opportunity to understand and appreciate how these complex relationships are managed. I shall therefore turn to how our respondents dealt with these negotiations and the light in which they came to see both family and friends.

\section{Reactions from kin and friends}

Our interviewees identified broadly three types of responses that they had to manage and negotiate. These were not entirely discrete and could overlap at the margins, nor were they always unambiguous; for example, parents might be pleased for their son or daughter but anxious about publicity. It was also the case that mothers might respond differently to fathers, or brothers to sisters, and this meant that different relatives came to occupy shifting emotional spaces of different significance in the process. For example in the case of Will and Richard it was hugely significant for Richard that his brother gave him away, even though the brother had previously been quite negative about his sexuality. We were also told stories of friends and family changing their responses between the time of the announcement and the actual ceremony, initially declining to come (or failing to rsvp to the invitation) and then arriving on the day. This indicated that some family and friends needed time to work out their reactions to the planned event and were probably weighing up issues of conflicting feelings or principles. These responses can be organised under the headings of positive, ambivalent and negative and I shall explore the contours of each of these in turn.

\section{Positive responses}

Family responses ranged from treating a son or daughter's same sex marriage as a matter for celebration in the family, to making economic provision, to renaming the new 'in-law' as son or daughter, and welcoming the social legitimacy given to their son or daughter's relationship. Chris and Sarah's experience was that their marriage had brought both sides of their families together, creating an extended kin network.

Chris (32 yrs): Yes it has sort of brought Sarah's family and my family more sort of like knitted together over the last couple of years; since we have been married we are really close.

Sarah (31 yrs): I mean when we go out and everything they [sibling] always introduce me as a sister-in-law. And it is like your mother and dad, they 
always introduce me as their daughter and they are perfectly - you could not really expect more than that could you?

Getting married could mean that parents expressed more affection and closeness because the marriage was apparently interpreted as a clear sign of love and commitment. As Sally below says, her partner Judy's parents, who had come to the ceremony, seemed able to become more relaxed about the whole thing afterwards.

Sally (34 yrs): And I said to your dad shall I call you father now and he said in all seriousness "Oh yes you should do." I don't know whether they see us any differently or whether or not it has given them permission to acknowledge us more, your mum and dad at least, to acknowledge us more. Because before it was never really discussed was it? I was accepted as your partner but our relationship was never mentioned.

The overwhelming majority of the couples expected close friends to be supportive, although not all felt they had large circles of friends which meant that their ceremonies were modest in terms of numbers. But the significance of the presence of friends was not measured in terms of numbers but in terms of who was there to witness the vows and enjoy the occasion with the couple. The significance of friends in this context appeared to be the way in which, as Weeks et al. (2001) argue, they provide confirmation of identity and belonging. Having friends there signified a proper recognition of the importance of their relationship, while also symbolising a strong form of connection with a personal community. But, although a few couples only wanted friends to be present, the majority saw it as an opportunity for mixing people together:

Audrey: Also I've got quite a lot of male gay friends and the people who came, particularly who came in the evening, they were overwhelmed to see how many of our family members were there, they didn't expect our family members to be there and they kept saying to me, "Well where's your dad?" and to see them all mingling in and being nice to everybody and everything going well....

This bringing together of different relationship networks was often seen as one of the most important outcomes of a wedding and this is a point I shall return to below.

\section{Ambivalent responses}

In the ambivalent category were included mainly those friends, parents, sibling and children who needed time to adjust to the idea. Some parents were taken aback because (at that time) they did not think that having a ceremony was something that same sex couples could do. In this group were the kin who had 
to be approached sensitively and with caution. With this group a considerable amount of emotional labour was required to gain acceptance. In some cases the couple decided not to tell their parents because they knew that it would be 'a step too far'.

Ella (38 yrs): The reason I didn't invite them was because we were actually getting on quite well, moving forward, all our hard work and they'd moved a long way within their world and we'd moved a long way within our world. I thought if I invite them now it will actually be a slap in the face and it's because things were going well that I knew that it was not the right time to present them with this particular issue.

This quotation reveals very clearly the way in which relationships with kin may have to be gently nurtured. Although it is often assumed that family ties are 'given' and can be activated and relied upon at will, Ella's account shows how delicate these ties may be and how much ethical balancing is required to sustain some relationships at all.

Initial objections from family members were not always to do with a lack of acceptance of homosexuality however. A few couples had parents who were ideologically opposed to marriage itself:

Hanna (44 yrs): They have different responses though don't they because I think my mum is a bit of a feminist and her objection is the institution of marriage and I think maybe your family it is the women thing that they are not happy with. Because your mum does not like the word lesbian; she does not like it, does she?

Others had parents who were religious and who felt that their principles would be too compromised to come to a ceremony. Sometimes these parents came to the party afterwards but would not come to the ceremony itself.

While negotiations with parents could be awkward, negotiations with children could be more emotionally taxing. This was because maintaining a positive relationship with children appeared to be even more important than doing so with parents. Rejection by parents, especially if they were deemed to be 'old fashioned' or highly religious, was hurtful but could be put in context and managed; but rejection by children was much harder to handle emotionally.

Gillian (45): When I told the kids, I said I had something to tell them and the older one went 'Ergh! please tell me you are not having a wedding', and I went 'Well something like that' and they were a bit sort of - they were alright. ... But now they have both said they are happy for me and then the other day [my daughter] came out and said 'Mum I would like to make a speech at your ceremony', which was quite nice and they quite want to be involved. Because when I first told them that I was gay they were horrified, 
absolutely horrified and I sort of lost them really for about three years really, but then they came back and you know we get on really well now.

Friends could also withdraw or become rather silent at just the time when they might be expected to be actively supportive or happy about the planned event. As Weston (1997) has argued it is problematic to assume that chosen relationships do not have conflicts of values and feelings too.

Annemarie (27 yrs): And some of our friends they did not really say anything, but some did not come and, well you never know about the reasons, but some were not really convincing.

This coolness by some friends was something that almost all couples experienced, but it was only really significant if close friends became distant or unresponsive. What was interesting was that few of the friends who became 'cool' and withdrawn appeared to explain their reactions in terms of an ideological or political rejection of marriage. They were more likely to say they were out of town, or that they had a previous engagement, than to say they disapproved. Obviously their 'real' feelings are not something we can know from this study, but it was clear that many couples felt that the reasons these friends gave for their absence or their lack of enthusiasm were spurious. But this gave rise to suspicions of a personal reason or problem rather than a political objection. This explanation offered by Cameron was fairly typical of the kind of interpretation we were offered:

Cameron (44 yrs): I think if anybody felt a little bit awkward perhaps it might have been one or two of the gay couples we know who were there because it would raise the question 'Do they want such a thing?' They could see that we were enjoying ourselves and it was fun for us, but what was it saying about them? Should they be doing something similar? Do they want to do something similar? We have had one or two serious discussions since with gay friends about how they felt with it and we did not have anyone taking a more radical stand saying 'Why are you doing something that is so, that is aimed at straight people?' because it might well seem that is what we were doing. But perhaps it is because we do not have friends who would perhaps think that but I am sure some gay people would think that.

In this explanation Cameron excludes the possibility of an overt political agenda being the problem but there may have been more subtle or micro 'political' issues at stake because, as Lannutti's (2005) study ${ }^{8}$ showed, the growth of same sex marriage may generate an anxiety that married friends will be lost to the LGBT network by 'settling down' into coupledom. So the reaction of some of these friends might have been a complex mixture of political and personal concerns. 


\section{Negative responses}

Livia (36 yrs): At that time, both our parents were against it completely, our relationship, and it was like, "F*** it, well our friends are for us so let's do it with our friends and let's have a good time".

Parents who had never accepted their son's or daughter's sexuality were never expected to accept their marriage. Some reportedly became even more dismayed because the announcement finally quashed all their hopes that their son or daughter was going through a 'phase'. And in yet other cases, the announcement was treated with considerable shock as if the parents had 'forgotten' that their son or daughter was homosexual. For the lesbians and gay men we interviewed this was experienced as a kind of second coming out and it was accompanied by the same kind of emotional distress as the first time. Sometimes it gave rise to sadness and at other times anger or exasperation. In the case of Erin (23 years) and Sam (24 years) neither sets of parents were supportive. Erin was a Christian and had found a Church which accepted her sexuality and was prepared to bless her union, but her parents' reading of Christianity meant that they could not accept her sexuality at all. Sam's parents were perfectly relaxed about her sexuality, but could not accept the fact that she had become a Christian:

Sam (24): Well my family are completely OK about my sexuality because of the fact that I come from Southtown, you know, and my parents are relatively hippyish in their lifestyle previous to having children and stuff. So they have alternative ideas and are just generally quite modern in that way. But they have quite large issues over the fact that I go to church.

Where relationships were really bad or where there was little point in even thinking of a reconciliation, parents and other family members were not informed of the ceremony let alone invited. This avoided the possibility of the occasion being spoilt or the problem of seating plans and/or awkwardness at the reception. In these cases couples could take steps to avoid problems or rejection but when it came to outright rejection by friends they were often not so prepared and were taken aback.

Outright rejection was typically expressed in overtly political terms with friends questioning why a couple would adopt straight values, or would wish to conform to the standards of the dominant heterosexual value system.

Frank (39 yrs): Funnily enough Steve, who was the mutual friend who asked us both to get together, was not able to come because he was out of the city at the time. But he did say had he been in the city, he would have refused to have come. And another friend made a slightly pointed remark. But a remark as in a little 'Oh, what are you taking heterosexual values for?' But there was very little of that going on. That was Steve, yes that was his 
professed reason why he would have made a stand against it. It was buying into the heteronormativities - that system - which I appreciate and respect, and think he is wrong.

Although we encountered very few examples of this sort of reaction we have no way of knowing how extensive the kinds of views held by Steve might be. It is possible that decisions to get married may put strains on some friendships where people find that they have rather different political perspectives or values. Even some of the individuals we interviewed volunteered the information that they had been against same-sex marriage themselves and so it is highly likely that amongst their friends there would be dissenters. Unfortunately this study could not track how such differences were managed over time and whether rifts appeared in previously strong relationships.

\section{Concluding remarks}

In this paper I have taken the fateful moment of a commitment ceremony and/or planned civil partnership to explore how this life event impacts upon close personal relationships. The focus of the study was directed towards the constellation of events and negotiations around the 'announcement' and the ceremony itself rather than on long term consequences (see Shipman and Smart, 2007). But importantly a critical moment such as a wedding takes everyday relationships out of their normal routine because people are forced to confront feelings which otherwise might be glossed over. This was true for all our couples because even those who had very supportive families and friends had at least one person (an aunt, cousin or old school friend) who presented some kind of personal problem for them. No one in the study was untouched by these issues even if the problem was about acceptance of same-sex relationships or about rejection of perceived heteronormative and patriarchal practices like marriage.

Most importantly for an understanding of the process of negotiating and maintaining both given and chosen relationships was the insight the interviews provided on the lengths to which individuals would go to both to include kin as well as friends, and to style a ceremony and party which could bring everyone together. Indeed this bringing together (if only for a day) was often described as the main success of the whole process and considerable satisfaction was voiced by those whose kin attended and provided visible support. Their support was perhaps most remarked precisely because it could not necessarily or automatically be relied upon.

The issue that remains to be discussed is what this study might contribute to the current debate about the relative meaning(s) and significance(s) of friends and family (Budgeon, 2006). I point out above that Pahl and Spencer have identified a 'blurring of boundaries or suffusion between the content of chosen and given relationships' and so they argue that it is problematic now 
to focus 'solely on one side or other of the equation' (Pahl and Spencer, 2004: 203). In order to avoid the pre-determining (even over-determining) categories of friends and family they therefore develop the concept of 'personal communities' which are not pinned down or conceptually restricted by place (physical locality), type (eg work colleague) or affinity (mother, acquaintance etc). They go on to produce a complex and detailed typology of relationships which still uses the concepts of friends and family as descriptors but which succeeds in revealing the complex mix of different relationships (with their different meanings, purposes and degrees of closeness) that constitute personal communities. Pahl and Spencer are trying to achieve a different form of sociological conceptualisation of relationships while recognising that terms like family and friends continue to have huge cultural significance and meaning in everyday life. So it is not that they seek to expunge terms such as family or friends from the sociological lexicon, rather they argue that they should not be conceptually determining. Moreover, they recognise that for some people interactions with family remain more important than with friends and vice versa so they do not seek to 'flatten out' all relationship types and make general statements about the respective fortunes of either families or friends in (post)modern times. In line with Pahl and Spencer, this study would not seek to make claims about whether friends are replacing families nor about whether one type of relationship takes a more radical or progressive form than another. Rather I have sought to delineate the relational landscape of a particular sample of same-sex couples and to show how varied and complex it can be. In this context Stychin's concern that a recognition of the significance of families of origin is to put 'gays ... not within families of choice, but back from whence they came: in their families of birth' (2003: 33-4) seems out of place, especially as he understands this to mean that the 'traditional' family (his terminology) reasserts itself, thus negating the value of families of choice. Stychin's argument is based precisely on a conceptualisation of family which is elsewhere being rendered problematic (Weston, 1997: 22; Lewin, 1998: 90). It also presumes that there is a one directional flow between families of origin and their gay sons and lesbian daughters through which the family enfolds the child back into heterosexual and 'traditional' family values while we found that gay and lesbian children could change their families of origin. Our study, when combined with other recent empirical studies of relationships (Ribbens McCarthy et al., 2003; Edwards, 2000; Carsten, 2004), would suggest that it is important to gain an understanding of what Pahl and Spencer would call 'personal communities' from the ways in which people are themselves negotiating, redefining, and accommodating to different relationships rather than from imposing meaning derived from preconceived assumptions about the relative merits of families and friends. 


\section{Notes}

1 Although 'marriage' is not the officially preferred term for civil partnership there is every indication that it has already become the colloquial one so we use it here as well as the term wedding.

2 See the Special Issue of Feminism and Psychology 2004, 14(1) for a range of views.

3 Rosie Harding (2006: 512) makes a similar point when she argues that recent debates have rarely investigated the views of 'ordinary' lesbians and gay men.

4 Professor Jennifer Mason and Ms Beccy Shipman worked with me on this study of gay and lesbian marriage. Beccy carried out all the interviews but we worked as a team. This means that I refer to the data collected as 'ours'. However this particular paper is the result of my own analysis and so I move from expressing collective 'ownership' to individual authorship in this text. This is quite deliberate. The study was carried out shortly before the introduction of Civil Partnerships in the UK and hence I specifically refer to marriage here to distinguish it from the later legally recognised contract of Civil Partnership. At the time of the study it was not only possible for couples to organise their own (informal) weddings which had no legal significance but in many cities and towns they could also register their partnership with their Local Authority in order to benefit from some forms of local provision (eg regarding social housing) or simply to make more formal and public their commitment to one another.

5 This study was funded by the ESRC ref R 000230418 .

$6 \mathrm{We}$ are grateful to Matthew Weait for his help in this.

7 For example Morgan (1996); Weeks et al. (2001); Dalton and Bielby (2000); Barrett and McIntosh (1982).

8 Lannutti (2005) discusses how 288 LGBT men and women in the USA, in responding to a web-based survey on the impact of same-sex marriage, expressed a range of concerns about the benefits and disadvantages of the legal marriage for the LGBT community. In her conclusion, Lannutti argues that same-sex marriage is a complex cultural event and she is critical of those who adopt a simplistic 'pro' or 'anti' approach because her findings suggest that there is a much more complex and subtle response going on in the LGBT community.

\section{References}

Auchmuty, R., (2004), 'Same-sex Marriage Revived: Feminist Critique and legal Strategy', Feminism \& Psychology, 14 (1): 101-126.

Barrett, M. and McIntosh, M., (1982), The Anti-Social Family, London: Verso.

Bech, H., (1992), 'Report from a Rotten State: "Marriage" and "Homosexuality" in "Denmark" , in K. Plummer (ed.) Modern Homosexualities, London: Routledge.

Bell, M., (2004), 'Holding Back the Tide? Cross-Border Recognition of Same-Sex Partnerships within the European Union' European Review of Private Law, 5: 613-632.

Boyd, S. and Young, C., (2003), "From Same Sex to No Sex"?: Trends Towards Recognition of (Same-Sex) Relationships in Canada', Seattle Journal for Social Justice, 1 (3): 757-793.

Budgeon, S., (2006), 'Friendship and Formations of Sociality in Late Modernity: the Challenge of "Post Traditional Intimacy", Sociological Research Online, 11 (3).

Carsten, J., (2004), After Kinship, Cambridge: Cambridge University Press.

Clarke, V. Burgoyne, C. and Burns, M., (2006), 'Just a piece of paper? A qualitative exploration of same-sex couple's multiple conceptions of civil partnership and marriage', Lesbian \& Gay Psychology Review, 7 (2): 141-161.

Dalton, S.E. and Bielby, D.D., (2000), “"That's Our Kind of Constellation”: Lesbian Mothers Negotiate Instutionalized Understandings of Gender with the Family', Gender \& Society, 14 (1): $36-61$. 
Dunne, G.A., (1997), Lesbian Lifestyles: Women's Work and the Politics of Sexuality, Basingstoke: Macmillan.

Edwards, J., (2000), Born and Bred, Oxford: Oxford University Press.

Finch, J. and Mason, J., (1993), Negotiating Family Responsibilities, London: Tavistock/Routledge.

Finch, J. and Mason, J., (2000), Passing On: Kinship and Inheritance in England, London: Routledge.

Giddens, A., (1992), The Transformation of Intimacy, Cambridge: Polity Press.

Gillis, J., (1996), A World of Their Own Making, Boston, Massachusetts: Harvard University Press Harding, R., (2006), “ "Dogs Are 'Registered', People Shouldn't Be”: Legal Consciousness and Lesbian and Gay Rights', Social \& Legal Studies, 15 (4): 511-533.

Jeffreys, S., (2004), 'The Need to Abolish Marriage', Feminism and Psychology, 14 (2): 327-331.

Lannutti, P., (2005), 'For better of worse: Exploring the meanings of same-sex marriage within the lesbian, gay, bisexual and transgendered community' Journal of Social and Personal Relationships, 22 (1): 5-18.

Lewin, E., (1998), Recognizing Ourselves: Ceremonies of Lesbian and Gay Commitment, New York: Columbia University Press.

Mansfield, P. and Collard, J., (1988), The Beginning of the Rest of your Life? Basingstoke: Macmillan.

Murphy, J., (2002), 'The Recognition of Same-Sex Families in Britain: The role of private international law', International Journal of Law, Policy and the Family, 16: 181-201.

Murphy, J., (2004), 'Same-sex marriage in England: a role for human rights?' Child and Family Law Quarterly, 16 (3): 245-258.

Nardi, P., (1992), 'That's What Friends Are For: Friends as family in the gay and lesbian community', in K. Plummer (ed.), Modern Homosexualities, London: Routledge.

Pahl, R. and Pevalin, D., (2005), 'Between family and friends: a longitudinal study of friendship choice', British Journal of Sociology, 56 (3): 433-450.

Pahl, R. and Spencer, L., (2004), 'Personal Communities: Not Simply Families of "Fate" or "Choice" ', Current Sociology 52 (2): 199-221.

Ribbens McCarthy, J., Edwards, R. and Gillies,V., (2003), Making Families: Moral tales of parenting and step-parenting, Durham: Sociologypress.

Roseneil, S. and Budgeon, S., (2004), 'Cultures of Intimacy and Care Beyond "the Family": Personal Life and Social change in the Early $21^{\text {st }}$ Century', Current Sociology, 52 (2): 135-159.

Shipman, B. and Smart, C., (2007), “'It's made a huge difference”: Recognition, Rights and the Personal Significance of Civil Partnership', Sociological Research Online, 22 (1): January.

Stonewall, (2004), Civil Partnership: Bill Parliamentary Briefing. House of Commons, Second Reading Tuesday 12 October 2004. www.stonewall.org.uk/documents/oahq_Commons_ Second_Reading_Sep_2004.doc

Stychin, C., (2003), Governing Sexuality, Oxford: Hart Publishing.

Warner, M., (1999), The Trouble with Normal: Sex, Politics and the Ethics of Queer Life, New York: The Free Press.

Weeks, J., Heaphy, B. and Donovan, C., (2001), Same Sex Intimacies: Families of Choice and Other Life Experiments, London: Routledge.

Weston, K., (1997, ${ }^{\text {nd }}$ edition), Families We Choose: Lesbians, Gays, Kinship, New York: Columbia University Press.

Wise, S. and Stanley, L., (2004), 'Beyond Marriage: "The Less Said about Love and Life-Long Continuance Together the Better" ', Feminism \& Psychology, 14 (2): 332-343. 